\title{
Hunger as a Constitutive Property of a Culinary Work
}

\author{
Fabio Bacchini ${ }^{1}$ (1) \\ Accepted: 3 October 2020 / Published online: 12 October 2020 \\ (c) The Author(s) 2020
}

\begin{abstract}
In this paper I attempt to show that a certain degree of hunger, intended as a material and psychological condition of the diner, can become a constitutive property of a culinary work. One may believe that the best possible argument supporting this thesis is one relying on the general assertion that an author's stipulative authority over the features of his or her work, if adequately exercised, is absolute. Quite the contrary, I show that we should prefer a different and more specific argumentative strategy based on the twofold fact that the conventions ruling over culinary works are peculiarly less stringent than in many other art fields, and that hunger has a very special status with regard to culinary works, in the sense that fixing the degree of hunger of the diner may serve to fix the appropriate conditions for any minimally acceptable perceptual experience of a culinary work to take place.
\end{abstract}

Keywords Hunger $\cdot$ Satiety $\cdot$ Culinary work $\cdot$ Food ontology $\cdot$ Ontology of art $\cdot$ Author's stipulative authority

Hunger can be defined as "the array of physiological and psychological states that distinctively promote, accompany and follow the human act of eating" (Borghini 2016). Such a definition has the virtue of considering the physical pangs of weakness and discomfort that we get when we need something to eat, and the psychological longing for food, as equally fundamental components of hunger (Telfer 1996). Of course we also "need to take seriously the very slipperiness of hunger" as a cultural category (Vernon 2007, p. 8). It is reasonable to assume, however, that rejecting the idea that hunger be merely a condition grounded in the material reality of the body, and paying close attention to its psychological aspects, necessarily results in taking into account its changing and historically specific forms.

This paper deals with a very particular question: can a cook successfully fix a certain degree of hunger, intended as a material and psychological condition of the diner, as a constitutive property of the culinary work he or she is the author of? Imagine that Miriam - a chef in a restaurant or hotel-creates a new culinary work and publicly declares that a diner can truly assert to be having a perceptual experience of that culinary work only if he or she is experiencing hunger pains while eating the edible matter plated up and

Fabio Bacchini

bacchini@uniss.it

1 University of Sassari, Alghero, SS, Italy served. If, on the contrary, the diner is not very hungry while eating, what he or she is having a perceptual experience of is just food, and possibly another culinary work - but certainly not hers. The question I am raising is whether and under what conditions Miriam can successfully stipulate this feature of her work. Trying to answer this question will force us to focus our attention on the relationship between hunger and the aesthetics of food-an issue that remains largely unexplored - and, at the same time, to investigate the limits of the authority of the cook to fix the constitutive properties of his or her culinary work, seen as part of a general theory of the authority of the author over the features of his or her work.

The two subjects of the role of hunger in the aesthetics of food, and of the authority of the cook over the features of his or her work, are very intertwined. For one thing, even if we had a general theory concerning the limits of the artist's stipulative authority over the features of his or her work, we may deem it unable to be appropriately applied to the cooking case by virtue of culinary works being not (always) works of art; and, culinary works may be not (always) works of art by virtue of our aesthetic appreciation of them being typically corrupted by hunger and our inextinguishable need to feed ourselves. ${ }^{1}$ I will try to prevent such an impasse, on one side, by assuming that any good theory concerning the artist's stipulative authority can be easily changed into a

\footnotetext{
${ }^{1}$ As Plato famously put it in the Republic, the pleasures of food are false pleasures, because they depend on a previous desire and really are only reliefs from pain; see Telfer (1996, p. 32) on this point.
} 
satisfying theory concerning the author's stipulative authority (as I am going to show, culinary works are a sort of things that, in some cases, are authored); and, on the other side, by rejecting the presumption that all or even some culinary works are not works of art in their own right. Nonetheless, I will consider the question whether cooking is, always or on some occasions, art, as beyond the scope of the present paper.

I will start by offering an apparently valid argument supporting the thesis that the author of a culinary work has the power to stipulate that a certain degree of hunger is a constitutive property of that culinary work.

\section{A Promising Argument}

Let us consider this argument:

(1) There are such things as culinary works;

(2) Some culinary works are authored;

(3) The author's stipulative authority over the features of his or her work, if exercised through adequate actions and communications, is absolute;

Therefore,

(4) The author of a culinary work can stipulate that a certain degree of hunger is a constitutive property of that culinary work.

Is this argument convincing? It appears deductively valid, so that its cogency seems to depend on the persuasiveness of the premises. Therefore I will examine the premises one by one. The result of my analysis, however, will be that-while all the three premises are true-the argument is actually invalid, and (4) does not deductively follow. This discovery will urge me to seek a different argumentative strategy in order to support my thesis.

Let us begin from premise (1). According to (1), also culinary works do exist in the world along with foods, dishes, ${ }^{2}$ cooks and kitchens, just like literary works exist in the world along with books and hand-written papers, and musical works exist in the world along with sequences of sounds and concerts. Indeed, a history of human ingeniousness in cooking is almost necessarily a history of ingenious culinary works - rather than ingenious foods and dishes—succeeding each other in time.

One could object that that of culinary work is an unnecessary and phantasmal notion, and that we should adopt a healthy form of eliminativism with regard to it. Only foods,

\footnotetext{
${ }^{2}$ Following Borghini (2015), I will assume that anything that is ready for someone to be eaten up is a dish. Unless differently specified, I will take a dish to be an edible concrete particular.
}

ingredients and dishes really exist. Culinary works should be either identified with these kinds of entities or eliminated.

I believe, however, that it can be shown how we need to postulate culinary works as a sort of things that exist in their own right. We may ask ourselves, for example, what I am having an experience of if I am eating just now a Big Mac in one of McDonald's restaurants. As a matter of fact, the edible concrete particular I am chewing is just a few minutes old. So I am certainly having an experience of an item that is just a few minutes old. But in another sense, I am having an experience of something that has been invented in 1967 by Jim Delligatti, the local operator of several McDonald's in the American state of Pennsylvania who first conceived the Big Mac and started serving it at his Uniontown McDonald's in April 1967 for 45 cents. It is only to this entity that we can ascribe whatever amount of ingeniousness we ascribe to the Big Mac and that I might be aesthetically appreciating while chewing. And, it is only to this entity that we can attribute the rightful place in a history of human cooking we assign to the Big Mac. I claim that the best characterisation of this entity is thinking of it as the culinary work 'Big Mac'.

The very same distinction emerges as opportune in classical music, where-if I am listening to a pianist playing the Goldberg Variations today-I am certainly having an experience of an item that is being created today-let us call it 'a complex sound event' - but I am also having an experience of a different sort of thing that was created in 1741 by J.S. Bach. It is only to this entity, which is commonly referred to as 'the musical work called 'Goldberg Variations' by J.S. Bach', that we can legitimately attribute the ingeniousness and originality I am aesthetically appreciating just now. Hence we should acknowledge the culinary work 'Big Mac' as a multiply realisable abstract entity, just like we acknowledge the musical work 'Goldberg Variations' as a multiply realisable abstract entity. ${ }^{3}$

An advocate of eliminativism about culinary works may rebut my claim by saying that, in the Big Mac case, we do have a more solidly existing item to which we can attribute all of the historically relevant aesthetic worth we may want to acknowledge to the Big Mac, that is, the recipe invented by Deligatti in 1967, which indeed seems infinitely executable. ${ }^{4} \mathrm{~A}$ world equipped with foods, dishes, ingredients, and recipes, is - ontologically speaking — a perfectly adequate world for those reflecting about the aesthetics of food.

\footnotetext{
${ }^{3}$ I am aware that there are many ontological accounts of musical works on offer. For a defence of the view of musical works as multiply realisable abstract entities, see e.g. Dodd (2007).

4 "A recipe-in first approximation-comprises the array of repeatable aspects of a dish whose replication would deliver a dish of the same sort" (Borghini 2016, p. 722).
} 
I think that this answer is not satisfying. First of all, the Big Mac-intended as the entity to which we can only attribute the ingeniousness and originality I am aesthetically appreciating while I am eating a concrete particular Big Mac-is not a recipe. Rather, it is determined by a recipe. This entity, and the recipe that determines it, may have very different properties, and notably very different aesthetic properties. The same goes for the relationship between the Goldberg Variations, intended as the entity to which we can attribute historically relevant aesthetic worth, and the musical score that fixes all and only its constitutive properties. Second, most traditional culinary entities of this sort-like, for example, Tagliatelle al ragù, Gazpacho and Moussakaare multiply realisable abstract entities, or types-hence they cannot be identified with any concrete particular dish-but cannot be associated with one and a single recipe. Rather, they are chased after, so to say, by a potentially infinite number of valid recipes. These recipes are not aimed at creating a new entity of this sort, but only at letting people produce an authentic and tasty instance of a well-established preexisting one. Therefore we cannot use recipes for identifying these kind of entities. Nor can we resort to ingredients or dishes. We really need to postulate them as entities in their own right. It seems to me only natural, then, to call them 'culinary works'.

Bacchini (2020) argues that there are three different kinds of culinary works. Some culinary works are edible concrete particulars, or dishes. But others are types; and among these, some are types that are specified by a recipe, while others are types independent of any recipe, that are rather run after by their recipes. I think we can take for granted that-especially by virtue of this latter kind of culinary works-the eliminativist position about culinary works is not tenable, and we must confirm (1).

Once we have embraced (1), approving (2) is very easy. It is true that many culinary works, like precisely most of those that are types independent of any recipe (which Bacchini calls 'of the second kind'), are unauthored. ${ }^{5}$ But many other culinary works, like most if not all those that are types determined by one recipe ('of the first kind') and most if not all those identical to an edible concrete particular ('of the third kind'), are authored. For example, the author of the Big Mac (a work of the first kind) is Jim Delligatti; and, the

\footnotetext{
${ }^{5}$ Because most culinary works of the second kind have slowly been shaped by selective pressures acting at the level of dish types, which are in competition for subsuming dish tokens. At the same time, the overall population of dish tokens evolved, also as an effect of the changing variety of the dish types. Of course, the recipes aimed at "hitting in its center" one of these types are often authored: but the culinary work is the type ("Tagliatelle al ragü"), not the recipe specifying how to prepare a good instance of that type, i.e. the subtype that-type-according-to-this-specific-recipe ("Tagliatelle al ragù my grandmother's way"). See Bacchini (2020).
}

authors of the Risotto Nino Borgese prepared by Eugenio Boer and modified by an improvised "twist" by Alberto Gipponi in Boer's restaurant one night in 2018 (a work of the third kind) are Eugenio Boer and Alberto Gipponi. ${ }^{6}$ Generally speaking, the author of a culinary work is the person, or the group of persons, who creates it and therefore deserves all the credit, or the blame, for its aesthetic worth and, more specifically, for the amount of ingeniousness and originality we attribute to it.

Note that only the author of a culinary work of the third kind is necessarily a cook, at least momentarily, in the sense that he or she must have physically prepared the dish that the culinary work consists in (but consider that some dishes do not need to be cooked and even manipulatedtake, for example, wild blackberries on the plant along a sunny roadway, hit by the performative utterance "Let this be my dish!" by someone momentarily acting as a cook; see Bacchini (2020) on this point). On the contrary, authors of a culinary work of the first kind do not need to be cooks: they are just those who stipulate all and only the constitutive properties of the work by authoring a work-determinative recipe. They do not need to prepare any instance of their work. When it comes to culinary works of the second kind, their authors-if any (see footnote 5) - are even a step further away from being cooks, since these works are types that can be "romanced" by a potentially infinite number of recipes whose authors, in turn, are not necessarily the cooks who execute them (and each recipe, in its turn, seems executable in an infinite number of different ways, each of which produces a different dish, and perhaps even a microbiologically different dish).

Now, should we subscribe to (3)? Its best defence has been recently provided by Irvin (2005), who has highlighted how contemporary works of art often have a deeply indeterminate nature, because we cannot say whether some features are constitutive to them or not just by observing them and by applying the relevant set of conventions - think of some contemporary works of art made from materials that decay over time, such as Irvin's favourite example, that is, Liz Magor's Time and Mrs. Tiber (1976) ${ }^{7}$ - and in such cases the only way to determine what are the features of the work is to appeal to the

\footnotetext{
${ }^{6}$ Bacchini (2020) argues that it is difficult, contrary to appearances, to identify a true culinary work of the third kind: we must "possess strong and unsurpassed arguments supporting the position that it is impossible to dismiss any of the properties of the concrete particular-or, at least, any from one set of properties making the concrete particular necessarily different from any other-as non-constitutive".

7 Time and Mrs. Tiber (1976) is a work by Liz Magor consisting of 53 jars of preserves displayed on open wooden shelves with other objects like recipe box, forks, glass tops, rubber sealers, metal lids,
} etc. 
artist's sanction. Irvin is persuasive when she argues that Magor has successfully changed her work by changing her initial sanction, that the materials forming her work had to be permitted to decay until the whole object came to its natural end, into her subsequent sanction that invasive conservation measures had to be undertaken and the work had to be no longer put on display and rather transferred to the gallery's Study Collection.

The artist's sanction, intended as "the artist's publicly accessible actions and communications" (id., p. 315) exercised in the appropriate contexts and in respect of the conventions operating in those contexts-for example, "giving the work a title, offering an artist statement to accompany the work, or instructing curators about conservation or the conditions of display" (id., p. 319)—is capable of fixing the boundaries of the work as well as of establishing whether a particular feature is an essential feature of the work or not. Irvin clarifies that she does not mean to say that the mere intentions, or behavioural dispositions, of the artist have such power: "the operative notion, on my view, is not the intention per se but effective intention, or intention that has been put into action in a specific way" (id., p. 321). In other words, the sanction must be successfully established. Another important point is that the artist's sanction cannot determine how the work should be interpreted, but only what the work is, or consists inwhich, of course, may have important effects on the nature of acceptable interpretations.

According to Irvin, there is a basic, implicit and ubiquitous way in which an artist sanctions particular features of his or her work, and it is by simply creating and presenting the work: "when an artist puts forward an object with certain features, he or she is sanctioning the set of artwork features that, given the context and the conventions connecting the object and the artwork, the suitably informed audience will take the artwork to have" (id., p. 322). Both in the cases in which such conventions have been implicitly accepted by the artist, and in the cases in which they have been modified or overturned, then, the artist's sanction is the fundamental operative notion to refer to in order to explain why the work has the constitutive properties it has.

Now, suppose that we are confident that, as advocated by Irvin, the artist's sanction can endow the work with certain features. This is, however, not sufficient for subscribing to (3). For, perhaps the power of the artist's sanction is not absolute: for example, "the conventions connecting the object and the artwork" might simply happen to be stronger than the artist's sanction, however adequately put in action. Nonetheless, there are some passages of her work where Irvin seems to allow to the artist's sanction a stipulative capacity potentially able to prevail on all occasions. If we succumb to the force of the most radical reading of Irvin's thesis, we can legitimately subscribe to (3). But should we?

\section{The Price of the Author's Absolute Stipulative Authority}

One could raise doubts about (3). According to these doubts, there certainly are cases in which the author's stipulative authority is ineffective, however appropriately exercised. Consider this fictional case:

The Van Gogh case: We know that Vincent Van Gogh publicly declared at relevant points during the production of Wheatfield Under Thunderclouds (1890) that among the essential features of this work had to be included new physical features at different moments in the future-that is, all the new physical features caused by a series of hard hammer blows to be delivered by the curators to the work in 2040, 2190, 2340 and so on.

I doubt that we would agree that the curators should obey Van Gogh. Irrespective to the fact that it is adequately put in action, the artist's sanction seems doomed to failure in this case. Why?

Most of us would not want the curators to obey Van Gogh because they believe that, in so doing, the curators would severely damage and eventually destroy Van Gogh's work. And, this is true also for those of us who would never question that Amanda Ross-Ho and Analia Saban, as artists, have the full stipulative authority to sanction some damages to the canvas in their Sieve (and 4 details) (2009) and Acrylic in Canvas with Ruptures: Grid (2010), respectively (not to mention the many works consisting in holes or slashes on the surface of monochrome canvases by Lucio Fontana).

The problem has to do with the 'painting' category. We do subsume Wheatfield Under Thunderclouds under the 'painting' category. And, the 'painting' category fixes severe constraints over what is admissible as a constitutive property and what is not for a work falling under it. Every work that is subsumed under it is subject to this normative force. What a painter normally does is implicitly relying on the "painting' category as the external authority that answers all of the questions concerning the ontological status of his or her work, its identity conditions, its constitutive and contingent properties, and so on. In turn, the way in which familiar art categories like 'painting', 'sculpture' and 'sonata' provide these answers is determined by "the beliefs and practises of those who ground and reground the reference of the relevant sortal terms" (Thomasson 2010), that is, by the beliefs and practises of all the people that refer to paintings in language and in dealing with them, i.e. in deciding whether one painting has been destroyed by fire or not, whether another painting has been moved to another museum without attempting to its identity, and so on.

Now, the traditional 'painting' category simply forbids that being hammered every one hundred and fifty years 
after production by people other than the author can become a constitutive property of a work falling under it, irrespective of the author's having adequately attempted to sanction the property. ${ }^{8}$

If this analysis is correct, however, Van Gogh might have been capable of successfully sanctioning that property had he managed to sanction Wheatfield Under Thunderclouds as being not a painting. If he had been capable of effectively stipulating that Wheatfield Under Thunderclouds really is an unconventional kind of work, among whose constitutive properties there is its merely appearing like a traditional painting, he would have been also easily able to sanction the work's being endowed with new constitutive physical properties every one hundred and fifty years. At that point, there would be no good reason to ignore his requests.

So we can reject the objection represented by The Van Gogh case, and embrace (3), in so far as we can subscribe to the thesis that the author's stipulative authority over the art form the work belongs in, if exercised through adequate actions and communications, is absolute.

Indeed, there are very good reasons for subscribing to this thesis. Thomasson $(2005,2010)$ has developed a persuasive general theory of what determines the ontological kind to which a work belongs. According to this theory, it is the beliefs and practises of all the people that continuously refer to a specific work of art that determine what art kind that work belongs in in the first instance. But how do all these people, in turn, determine how they should have to do with that work in language and in other respects? How do they establish what they refer to by using the expression 'Wheatfield Under Thunderclouds'? According to Thomasson, "the public use of names for works of art (such as 'Guernica' or 'David') generally defers to the artist's original way of picking out the work, and so the artist is aptly considered the grounder of the name's reference" (2010, p. 122). So, an artist cannot change the ontological status of paintings, sculptures and symphonies; but what he or she can always do is to impose that the name that refers to his or her work is not used to refer to a work of a familiar art-sort.

Thomasson argues that we can take the artist to have sanctioned treating his or her work as a traditional art kind only in the absence of any counter-indications on his or her parts, and that the background conventions that in the latter situation determine the ontological status of the work are effectively violated each time that the artist does something explicitly and verbally-e.g. "filling in an 'artist's intent form" or "adding a clarifying statement to the work"-or

\footnotetext{
${ }^{8}$ Likewise, if something has to be a novel, its author cannot be effective in sanctioning that it be printed on paper rather than in digital form (see the attempts made by the Czech-born writer Milan Kundera) or in large print (Kundera (1993) himself reminds us that Franz Kafka tried to stipulate this feature for his novels).
}

implicitly and non-verbally, e.g. "correct[ing] or reject[ing] attempted displays by various galleries" or "set[ting] up the first display herself" (id., p. 125). "In any case, the key point $[\ldots]$ is that it is the artist who determines what (ontological) sort of thing she has created" (id., p. 126). In other words, the author's stipulative authority over the art form the work belongs in, if exercised through adequate actions and communications, is absolute. And this means, as said, that (3) holds.

But there is a problem: it is no longer true that (3) supports (4) in our argument. For, the price that an author may have paid for successfully stipulating that a certain degree of hunger of the diner is a constitutive property of his or her work is that that work is no longer a culinary work.

Now, it is possible to argue that the 'culinary work' category is not the same kind of category as 'painting', 'sculpture' and 'performance'. The art kinds that the author can always effectively sanction according to Thomasson are not the kind of kinds that the 'culinary work' kind belongs to. If this were true, an author might be uncapable of making his or her work not a culinary work also if he or she had to change the art kind the work belongs to in order to manage to stipulate a certain degree of hunger as a constitutive property of the work. For example, an author may manage to make a certain degree of hunger constitutive to his or her work by stipulating the work's belonging to the performance art category, but - presumably because the fact that the work exists necessarily requires that someone can be fed by means of it - the work would continue being a culinary work, too.

But this idea is very problematic. For, what kind (of the kind an author can always effectively sanction) would the culinary work have been before being transformed by its author's sanction into a work belonging to the performance art category? A sculpture, or a painting? This is totally unconvincing. If Tagliatelle al ragù and Big Mac are works at all—and, as we have seen, they are-what kind (of the kind an author can always sanction) would they be if not the 'culinary' kind?

I prefer, then, to subscribe to the position that the 'culinary work' kind - along with those of 'musical work', 'pictorial work' or 'painting', and so on-is one of the kinds that the author has always the power of effectively (positively or negatively) sanctioning. If so, the argument going from (1), (2) and (3) to (4) is not valid. Also in case (1), (2) and (3) were all true-and actually I have showed that they are -, (4) might be false, because it is possible that the author has managed to stipulate a certain degree of hunger as a feature of his or her work just by making that work cease being a culinary work. So we need a different defence of (4).

I will now try to show that nothing prevents a certain degree of hunger from becoming a constitutive property of a culinary work if his or her author adequately sanctions it so. In fact, the conventions ruling over culinary works are 
jointly less stringent than in other fields; and, in particular they do not exclude hunger from the features that can be manipulated by their authors. Rather, hunger has a very special status with regard to culinary works: I shall argue that this status amply justifies (4).

\section{Hunger and Its Special Status with Regard to Culinary Works}

It can be shown that the conventions ruling over culinary works are peculiarly less stringent than in many other art fields. For one thing, while most art fields are either invariably one-stage or invariably two-stage (Goodman 1968), cooking is sometimes one-stage (the works being the concrete particulars ready to eat) and at other times two-stage (the works being multiply realisable abstract entities), as we have seen above. More important, culinary works can be regarded as either objects or events, or perhaps better, as either occurrents or continuants (Simons 2000) (interestingly, if a culinary work is to be an occurrent, we cannot in the strict sense eat it or its instances, although we can enjoy it or its instances by eating the food that it or its instances employ for occurring); and, also, culinary works can be identified narrowly or broadly. On a narrow view, the spatial boundaries of the culinary work coincide with the edible matter that can be plated up and served, and its properties are limited to the intrinsic physical and microbiological properties of the edible matter itself; on a broad view, on the contrary, the spatial boundaries of the culinary work can be much more extended than that, and also, the work can possess much more kinds of properties.

Perhaps only architectural works enjoy such a degree of ontological permissiveness among traditional kinds of works (Bacchini 2018). For example, painting is invariably a onestage art whose products-pictorial works-are invariably concrete particular continuants identified narrowly, meaning that the only constitutive properties supervene on the physical marks on the surface of the canvas, while the back of the canvas, for one thing, cannot in any case count as part of the work. On the contrary, while some culinary works are similar to paintings in their being concrete particular continuants that can be identified narrowly-take, for example, some works by Gualtiero Marchesi-some others, like those created by Paul Pairet for his single-table restaurant Ultraviolet (opened in 2012 in Shanghai) and among whose essential ingredients are lights, projections, sounds, music, scents, air flow and temperature, are rather multiply realisable abstract occurrents to be identified broadly (ibidem).

In this context, introducing the hunger of the diner as a constitutive property is not problematic. For sure, it is not by appealing to our duty to preserve the integrity of the work, as in The Van Gogh case, that we can raise doubts over the legitimacy of such a move, because cooking is special in that each concrete particular (be it the work or one of its instances) is necessarily destroyed (or brought to an end, if it is an occurrent) by the one person that has a full experience of it, irrespective of his or her being hungry or sated.

More relevantly, hunger cannot be considered as a too specific and bizarre feature to be made constitutive of a culinary work. My argument, here, is that there are features much more specific and bizarre than hunger that have been successfully sanctioned as constitutive properties of a culinary work.

Take, for example, Vibrazioni-Gioco al Cioccolato 2018 by Massimiliano Alajmo, a dessert served in Le Calandre (Rubano, Padua) as a dark squared board with sixteen tastings on top and a pair of headphones that the waiter invites you to wear. It is the diner who creates the sounds that echo in his or her ears. Every gesture, with or without cutlery, is amplified thanks to a series of sensors placed on the surface of the plate. So you can listen to "the crackling of the crispy flakes of chocolate with tonka beans", "the spoon dipping into the mango and passion fruit spumoni", "the crispiness of the Buckwheat crostolo with gianduia and powdered spices" and so on (Zanatta 2018). The auditory experience, intended as a condition under which the aesthetic appreciation of the work may take place, is effectively sanctioned by Alajmo as a constitutive property of his culinary work. A dessert is not Alajmo's Vibrazioni-Gioco al Cioccolato 2018 if the diner refuses to wear the headphones or is deaf, irrespective of the eatable matter's being microphysically identical to that constituting it. The same holds for Heston Blumenthal's The Sound of the Sea and Nino Di Costanzo's Napule è, requiring the diner to be listening to an iPod playing the sound of seagulls flying over the cliffs of the Channel, and the homonymous song by songwriter Pino Daniele, respectively, while eating the edible stuff included in them.

But the history of cooking is literally full of culinary works incorporating unconventional properties as constitutive. Think of the countless recipes created by the members of the Italian Futurist Movement, such as Fillìa (Luigi Colombo)'s Aerovivanda (“Aerialmeal") (1931), a culinary work among whose essential features there is the property of being brought to the mouth by the right hand of a diner whose left hand must continuously tap a "tactile rectangle" made of sandpaper, red silk and black velvet, while the waiters spray onto his or her neck a carnation essence, and a violent co-noise ("conrumore") of an aircraft engine comes from the kitchen together with a dysmusic ("dismusica") by Bach (Marinetti and Fillìa 2018, pp. 208-209). Fillìa has certainly been effective in stipulating all these features, however very odd and strange, as constitutive of his culinary work. In fact, you cannot say you have experienced an instance of Aerovivanda if you have not had the required tactile, olfactory, visual and auditory sensations, regardless 
of you having eaten black olives, fennel hearts and Seville oranges, that are the eatable components of the work. At the same time, you cannot deny that Aerovivanda is a culinary work, the main reason arguably being that its author sanctioned it so and the public opinion has never challenged this sanction.

If the movements of the hands of the diner can become constitutive properties of a culinary work, even more so can his or her degree of hunger. For, hunger (along with satiety) seems to have a special status with regard to culinary works.

First of all, a certain degree of hunger of the diner can be a fundamental condition for any minimally acceptable perceptual experience of an individual culinary work to take place. To make an example, a ravenous diner will very likely experience Massimo Bottura's Cesar Salad in Emilia in such a way (e.g. by devouring it in one gulp) that necessarily makes him or her incapable of experiencing, and a fortiori of aesthetically appreciating, most if not all of the 22 "surprises" hidden in the leaves of a little, soft, buttery head of lettuce in which the work for the most part materially consists. Of course cooks have always thought of "the dining experience as a dialogue with the hunger of the diner" (Borghini 2016, p. 6), and from this point of view we can expect that Bottura will take precautions in order to prevent such an inappropriate enjoyment of the work, e.g. by proposing Cesar Salad in Emilia only as the fourth or the fifth course at least. Other cooks may serve some bread at the beginning of the meal, while Ferran Adrià in his restaurant El Bulli used to ask the diner to experience his Cocktail Spray, a Dry Martini sprayed into the mouth rather than sipped, explicitly conceived for taking away an anxious sense of hunger (Adrià also happened to serve buttered bread for this purpose). But the point, here, is that the diner's being not famished may be easily considered as constitutive to a culinary work such as Cesar Salad in Emilia. It would be not strange if Bottura declared that, in order for the heart of lettuce presented with the 22 different tiny ingredients hidden in it to be his Cesar Salad in Emilia, it is necessary that the diner be not famished, more or less like a spectator can only truly be said to be experiencing an IMAX $3 \mathrm{~d}$ film such as Avengers: Endgame (2019) if he or she is wearing 3d glasses (the images on the screen otherwise looking doubled and blurry). I claim that in this case (a) Bottura's sanction would be effective, and (b) Cesar Salad in Emilia would remain a culinary work after all. One could even argue that such a sanction was already implicit in the author's expertly hiding 22 carefully selected ingredients in the leaves of an apparently unadorned, halved, minuscule head of lettuce.

Of course, the same can be said about a cook's stipulation that the diner should be not satiated relatively to-for example-the aforementioned Adrià's Cocktail Spray. Or, we can easily imagine a culinary work requiring to be eaten voraciously in order to be appropriately perceived and aesthetically appreciated. ${ }^{9}$

One could object that normally the appropriate conditions for having a minimally acceptable perceptual experience of a work, or in any case for adequately aesthetically appreciating it, do not become in any way constitutive to that work. For example, Guernica is to be seen from the front: but being seen from the front seems not constitutive to it.

My answer to this objection is that an author can easily effectively sanction a property specifying one of the appropriate conditions for having a minimally acceptable perceptual experience of his or her work, or in any case for adequately aesthetically appreciating it, unless he or she has sanctioned (either through actions or omissions) treating the work as a traditional art kind that imposes stringent appropriate conditions for the aesthetic appreciation of the works subsumed under it.

So, for example, we could specify a long list of appropriate conditions for the aesthetic appreciation of Guernica (that it be hung flat on a wall so that the side with the marks on it is visible; that it be more or less at eye level; that it be adequately illuminated; that it be viewed from the front and from not too far away); but they are the same as for any possible painting (with very few exceptions), and indeed their holding relatively to Guernica is merely a consequence of Guernica's having been sanctioned by its author as a painting; none of them can be further sanctioned as constitutive to Guernica, partly because they are already included in the conventions ruling over paintings in virtue of their subsuming under the 'painting' category, and partly because these conventions seriously limit the kind of features that can become constitutive to any painting.

The same would surely happen with regard with hunger/ satiety and culinary works, if only the appropriate conditions for the aesthetic appreciation of culinary works relatively to hunger/satiety, and even more so in general, were always the same. But this is not the case. As I have showed, the conventions ruling over culinary works are jointly less stringent than in other fields. In particular, while some culinary works

\footnotetext{
${ }^{9}$ In the majority of cases, the author's explicit sanction seems crucial. Take the case of a quenching beverage like Gatorade: also if we assume, as many of us may attest, that it tastes best if consumed when thirsty, we presumably would want to say that we would still be drinking Gatorade if we drank it when quenched. The fact that Gatorade is explicitly designed to relieve thirst, along with its alleged not ceasing to be Gatorade even if consumed when quenched, should not be taken as evidence against the thesis that the author has the capacity to stipulate a certain degree of hunger (or thirst) as constitutive to his or her work: to put it simply, for an author to sanction that his or her work $X$ has the function of $P$-ing is not necessarily for him or her to sanction that $X$ 's $P$-ing is constitutive to $X$. Moreover, an author could also stipulate as constitutive to $X$ a specific degree of hunger (or thirst) that makes $X$ taste bad, or at least worse than its best. I thank an anonymous reviewer for raising these points.
} 
can only be adequately aesthetically appreciated if the diner is not hungry, others may require his or her hunger. The variable hunger/satiety is therefore a knob that the cook can turn at will to fix the right constitutive conditions of his or her culinary work individually, where necessary. ${ }^{10}$

On the other hand, if the conventions ruling over paintings were less severe than they are, painters would be capable to stipulate this or that condition as constitutive to their individual paintings. If, for example, the 'painting' category did not impose that any painting is to be seen from the front-suppose that a relevant subset of paintings were constituted of anamorphoses, i.e. distorted projections or perspectives requiring the viewer to occupy a specific vantage point to view a recognizable image, like the distorted shape lying diagonally across the bottom of the frame of The Ambassadors (c. 1533) by Hans Holbein the Younger, that viewed from the correct oblique angle transforms into a human skull-being seen from the front and being seen from an acute angle would be properties that, where implicitly or explicitly sanctioned by painters, would surely be capable of easily becoming constitutive to an individual painting.

Another reason for taking the degree of hunger of the diner as having a special status with regard to culinary works is that it is a measure of the degree of his or her recent deprivation or satiation of culinary works in general, and therefore of the embodied sense of attraction, indifference or repulsion that he or she will feel in response to culinary works in general, and in response to the individual culinary work under consideration in particular. ${ }^{11}$

Of course an author does have the stipulative authority to control the degree of attractiveness of a proper part of his or her work by adequately shaping other parts of it (for example, a dialogue in a novel can be intended as a restoring oasis following a very long descriptive passage); and, also,

\footnotetext{
${ }^{10}$ I therefore only partly agree with Sweeney (2012) when he argues that "hunger is the best sauce". I agree with his idea that, just as sauces "play a creative role in the ultimate character of a dish or a meal" (p. 67), so can a good appetite. But I think that each of the positions that the hunger/satiety knob can take can become constitutive to a culinary work-not only the position "healthy appetite".

11 We can refer in the same way to the "hunger" or "satiety" of a person listening to music or looking at paintings. As remarked by Sweeney (2012, p. 56), "for all appreciative experiences, our powers of discrimination and enjoyment can tire because of long periods of exposure or intense and demanding involvement. "Museum fatigue" is a known phenomenon.[...] Viewers will enjoy a few works more than they will enjoy trying to see everything in the collection, a project that will leave them bleary-eyed and exhausted. Listening to music for long periods also dulls one's powers of discrimination and capacity for enjoyment. Foregoing sleep and attempting to listen to all of Haydn's symphonies straight through - over a hundred-would be exhausting". On the other hand, "those who have developed a "taste" for painting and music can certainly feel deprived if for some reason they cannot listen to music or see works of art".
}

an author can often successfully control the degree of attractiveness of one of his or her works by stipulating the order in which a group of his or her works in which it is included must be experienced, and sometimes even how close in time these experiences must occur (think of a collection of poems or short stories, ${ }^{12}$ or a movies series like Edgar Reitz's Die Zweite Heimat (1993) and Krzysztof Kieślowski’s Dekalog (1989), or-also-a pop music album, or the installation of an individual exhibition). The latest condition also holds in cooking when a cook has the full control of the whole meal of a diner, and has therefore the power to make all the important decisions about the order and the temporal proximity of the diner's experiences of the culinary works he or she is preparing. (In this regard, it is interesting to ask whether it is possible, at least on some occasions, to consider the meal as the real culinary work, and the courses as its proper parts-a question that we can raise just as interestingly about individual exhibitions, pop music albums, movies series and collections of poems or short stories). But what we would need as a counterpart of the hunger case, however, is actually an author that manages to control the degree of attractiveness of one of his or her works by effectively stipulating the degree of the enjoyer's recent deprivation or satiation of works of the same art kind authored by other people (or, in any case, not authored by himself or herself). Such a situation is, at best, very infrequent.

It seems to me, however, that we can find out some examples in which this may happen. An architect could successfully require that, for her Isolated Villa not to be destroyed, the construction which the architectural work materially consists in must remain a long way away from any other building or human mark on nature, and difficult to reach. And, I guess that nothing would change if that architect specified that her sanction were motivated only by her intention to stipulate the user's hunger of architecture as a feature of the work. Likewise, an installation artist could be effective in stipulating that her installation work of art be experienced only after that the visitors of the museum have walked through a "depurative corridor" where no other work of art is exhibited.

In sum, the special status that hunger possesses relatively to culinary works, combined with the high degree of ontological permissiveness enjoyed by culinary works, gives us the right to claim that nothing prevents a certain degree of hunger from becoming a constitutive property of a culinary work if his or her author adequately sanctions it so.

\footnotetext{
12 According to Kundera (1993), it is both morally and aesthetically unbecoming that many editions of Franz Kafka's complete works, such as the French edition in the Bibliothèque de la Pléiade, insolently ignore his will that only some of his short stories be published, and, that they be grouped as in the original collections personally assembled by Kafka himself.
} 


\section{One Final Objection}

I have tried to show that the author of a culinary work can stipulate that a certain degree of hunger of the diner is a constitutive property of that culinary work. I have first attempted to support this conclusion using a very general argument which, unfortunately, has proved to be invalid. I have then tried a different argumentative strategy more sensitive to the particularity of cooking that, so it seems to me, achieves the purpose. Perhaps irrespective of my conclusion, we should take this kind of reflections as a first step towards a deeper investigation of the role of hunger in the aesthetics of food as well as about what are, under multiple points of view, the counterparts of hunger and satiety in art or activity kinds other than cooking.

I shall end by raising a general question that, I admit it, might be seen as an important objection to my conclusion. Since the diner's degree of hunger can be considered in any case also as a feature of that person's aesthetic experience of a culinary work, the question is to what extent it is acceptable, if it really is, that a feature of the aesthetic experience of a work is stipulated as a constitutive feature of the work itself.

In fact, it seems reasonable to believe that a work, along with all its constitutive properties, must be capable of being identified independently of any feature belonging to its possible aesthetic experiences. And this, in turn, is due to the fact that-again, reasonably — whether a work exists or not, and whether its ontology is of one sort or another, are issues that should not depend on the contingent fact that someone has ever an experience of that work or not. So, for example, the nature of Guernica, and indeed of any painting, is independent of its having been seen by one million, ten, one or zero people; similarly, the nature of the Goldberg Variations is not affected by its having been listened to by many people or nobody. Including a feature of the experience of the work among the constitutive properties of the work is refusing to acknowledge this point.

But there is even a more solid reason for raising concerns about such a possibility. Indeed, one could argue, the aesthetic experience of a work - or, of one of its features-cannot be part of the work itself. For, otherwise, aesthetically experiencing the work would require aesthetically experiencing one's aesthetically experiencing the work, and so on, the thesis resulting in infinite regress.

We could react to these difficulties by backing out and denying that the diner's hunger can be a constitutive property of a culinary work. But it is also possible, I argue, to deny that the diner's hunger is a feature of his or her experiencing the culinary work.

A first solution consists in distinguishing among features of an experience and conditions at which that experience is possible, and assuming that these two qualifications are mutually exclusive; now, if we take the culinary work as a bundle of conditions aimed at letting a specific aesthetic experience (i.e. the aesthetic experience of that culinary work) occur, a particular degree of hunger of the diner-by virtue of its being constitutive to the work-turns out to be a condition (not a feature) of the aesthetic experience of the work which does not entail or presuppose that any act of experiencing the work actually occur (exactly like as for any of the ingredients of the work).

A second solution consists in regarding the diner's hunger, first of all, as a feature of his or her experiencing of something different from the work itself-i.e., as a feature of his or her experiencing of the mere edible stuff-while at the same time claiming that the edible stuff is not the same thing as the culinary work.

But now, again, we have two different possible roads to follow. In the first case we concede that, if the edible stuff were a proper part of the culinary work, the infinite regress would still be a threat, arguably on the basis of the thesis that a feature of the experiencing of a proper part of $X$ necessarily is a feature of the experiencing of $X .{ }^{13}$ In this case, then, we need to be capable to deny that the edible stuff be a proper part of the culinary work. In order to achieve this goal we may say, for example, that if we consider the culinary work as an occurrent, then the edible stuff is just something that the culinary work uses in order to occur; and, something that an occurrent uses for occurring is not one of its parts. But then, this first version of the second solution would have the important defect of entailing that a certain degree of hunger of the diner can only be a constitutive property to culinary works that are occurrents rather than continuants, in so far as it is difficult to deny that the edible stuff is either the culinary work itself or one of its proper parts when the culinary work is a continuant.

The second version of the second solution consists in claiming that, even if the edible stuff is a proper part of the culinary work, nonetheless there is no infinite regress, because in this case the degree of hunger of the diner is only a feature of his or her experiencing of a proper part of the work, which is not the same thing as being a feature of his or her experiencing of the work itself. In fact, we can imagine that the experiencing of the edible stuff is a proper part of the culinary work, too, and that accordingly the experiencing of the culinary work incorporates the experiencing of such an experiencing and of all of its features (hunger included), without any infinite regress appearing. If we adopt the

\footnotetext{
13 Possibly, though not necessarily, because (a) a feature of the experiencing of a proper part of $X$ necessarily is a feature of a proper part of the experiencing of $X$, and (b) a feature of a proper part of the experiencing of $X$ necessarily is a feature of the experiencing of $X$.
} 
second solution in this second version, then, we can apply it also to culinary works that are continuants.

We must admit that the second solution offers a very limiting view of hunger in either of its versions, because it confines the aboutness of "the array of physiological and psychological states that distinctively promote, accompany and follow the human act of eating" to the edible stuff. Moreover, we should make sure that the occurrence of the diner's experiencing the edible stuff be not a necessary condition for the culinary work to exist: we may concede, for example, that the fact that a particular degree of hunger-as a feature of the diner's experiencing the edible stuff-is constitutive to the work only means that necessarily, if an experience of the work occurs, the subject of that experience must be that hungry.

I think that this is sufficient for showing that, however not simply, it is possible to reject the objection at issue. And this is enough, in turn, for confirming the conclusion that the author of a culinary work can stipulate that a particular degree of hunger of the diner be a constitutive property of that culinary work after all.

Funding Open access funding provided by Università degli Studi di Sassari within the CRUI-CARE Agreement. This work was supported by Fondo di Ateneo per la ricerca 2019, University of Sassari, Italy.

Open Access This article is licensed under a Creative Commons Attribution 4.0 International License, which permits use, sharing, adaptation, distribution and reproduction in any medium or format, as long as you give appropriate credit to the original author(s) and the source, provide a link to the Creative Commons licence, and indicate if changes were made. The images or other third party material in this article are included in the article's Creative Commons licence, unless indicated otherwise in a credit line to the material. If material is not included in the article's Creative Commons licence and your intended use is not permitted by statutory regulation or exceeds the permitted use, you will need to obtain permission directly from the copyright holder. To view a copy of this licence, visit http://creativecommons.org/licenses/by/4.0/.

\section{References}

Bacchini F (2018) The ontology of the architectural work and its closeness to the culinary work. City Territ Archit 5(1):5-21

Bacchini F (2020) Culinary works come in three ontological flavours. Humana. mente

Borghini A (2015) What is a recipe? J Agric Environ Ethics 28(4):719-738

Borghini A (2016) Hunger. In: Thompson PB, Kaplan DM (eds) Encyclopedia of food and agricultural ethics. Springer, Dordrecht

Dodd J (2007) Works of music: an essay in ontology. Oxford University Press, Oxford

Goodman N (1968) Languages of art. Bobbs-Merrill, Indianapolis

Irvin S (2005) The artist's sanction in contemporary art. J Aesthet Art Crit 63(4):315-326

Kundera M (1993) Testaments betrayed. Harper Collins, New York

Marinetti FT, Fillìa (2018) La cucina futurista. Il Formichiere, Foligno

Simons PM (2000) Continuants and occurrents. Proc Aristot Soc Suppl 74:59-75

Sweeney KW (2012) Hunger is the best sauce. In: Kaplan DM (ed) The philosophy of food. University of California Press, Berkeley

Telfer E (1996) Food for thought: philosophy and food. Routledge, London

Thomasson AL (2005) The ontology of art and knowledge in aesthetics. J Aesthet Art Crit 63(3):221-229

Thomasson AL (2010) Ontological innovation in art. J Aesthet Art Crit 68(2):119-130

Vernon J (2007) Hunger: a modern history. Harvard University Press, Cambridge, MA

Zanatta G (2018, May 10) Massimiliano Alajmo's Vibrazioni: listening to a dessert. Identità Golose. http://www.identitagolose.com/sito/ en/98/19628/zanattamente-buono/n-a.html

Publisher's Note Springer Nature remains neutral with regard to jurisdictional claims in published maps and institutional affiliations. 